\title{
A PARTICIPAÇÃO DAS MASSAS DE ARES NO INVERNO DE 2016 NO BRASIL
}

\author{
Victor da Assunção Borsato ${ }^{(a)}$ Erika Collischonn $^{(b)}$ \\ (a) Professor Associado, UNESPAR - Universidade Estadual do Paraná - Campus de Campo Mourão - \\ victorb@fecilcam.brou 1308victor@gmail.com \\ (b) Professora Adjunto do Departamento de Geografia, UFPel- Universidade Federal de Pelotas, Rio \\ Grande do Sul, ecollischonn@gmail.com.
}

\section{Eixo: Climatologia em diferentes níveis escalares: Mudanças e variabilidades}

\begin{abstract}
Resumo:
A tropicalidade do Brasil manifesta-se principalmente no regime das chuvas que, em grandes áreas do país é a primeira consequência da dinâmica dos sistemas atmosféricos. Para ampliar a compreensão da dinâmica, deveremos considerar os centros de ações, a estacionalidade e a dinâmica das massas de ares. A massa Polar ao avançar, no seu limite norte, área de contato com o ar mais quente e de densidade diferente geram os Sistemas Frontais, que, para o Sul do Brasil, causa os principais episódios de chuva. Para as demais regiões, atuam as massas de ares Tropical continental, Tropical atlântica, Equatorial atlântica e Equatorial continental. Considerando-se a hipótese de um ano atípico para 2016, traçaram-se como objetivo, contabilizar a participação dos sistemas atmosféricos para o Brasil na estação do inverno, elegendo-se nove estações climatológicas como referenciais. Os resultados mostraram que as participações das massas de ares mantiveram-se próximo do esperado para a estação.
\end{abstract}

\section{Palavras Chave: Climatologia Geográfica; sistemas atmosféricos;}

\section{Introdução}

Na Climatologia Geográfica do Brasil, dada a vastidão do território, é mais interessante caracterizar a dinâmica dos sistemas atmosféricos, a partir da compreensão da circulação geral e da participação e quantificação das massas de ares que atuam nos estados do tempo.

Neste trabalho, investigou-se a participação das massas de ares na estação do inverno de 2016, tanto no tempo cronológico, quanto nos diferentes quadrantes do território brasileiro. Considerou-se como hipótese principal, uma maior participação da $\mathrm{mPa}$ no tempo cronológico, visto que os principais meios de comunicações noticiaram que o inverno em curso estava sendo atípico, principalmente por conta da frequência em que as ondas de frio se sucederam para o Sul do Brasil.

A metodologia utilizada não dá subsídios para verificar a intensidade dos sistemas atmosféricos, embora a pressão atmosférica fosse lida diariamente e para todas as localidades consideradas. Para averiguar a intensidade seria necessário comparar com outros invernos; porém, não há estudos nessa linha de abordagem. 


\section{OS DESAFIOS DA GEOGRAFIA FÍSICA NA FRONTEIRA DO CONHECIMENTO \\ Instituto de Geociências - Unicamp \\ Campinas - SP \\ 28 de Junho à 02 de Julho de 2017}

As massas de ares que atuaram na estação do inverno foram interpretadas nas cartas sinóticas a partir de nove localidades sobre o Brasil e distribuídas pelas cinco regiões brasileiras. Contabilizou-se um sistema atmosférico por dia, considerando aquele que predominou nos dados. Os quantitativos em porcentagem foram especializados em mapas do Brasil para cada massa de ar. Dessa forma, além da quantificação tem-se a espacialização dos sistemas sobre o território brasileiro em seis mapas, considerando as cinco massas de ares e os Sistemas Frontais.

Por se tratar de um artigo, não se pode discorrer sobre as condições específicas dos sistemas atmosféricos para cada região geográfica do Brasil. Por isso, este estudo tratou de quantificar a participação das massas de ares para o Brasil, a partir de nove localidades. As quais foram especializadas e analisadas em conjunto.

Dada a grande extensão territorial e a dinâmica atmosférica para a estação do inverno, o extremo sul Brasil apresenta os maiores contrastes térmicos, pluviométricos e de episódios de ventos intensos. Estes contrastes, às vezes se ampliam e extrapolam a linha do trópico de Capricórnio.

Os resultados mostram a espacialização de cada massa de ar em território brasileiro, sendo que a massa Polar atlântica foi a que abrangeu as maiores extensões no Brasil, principalmente para os episódios em que ela avançou pelo interior do território.

\section{Procedimentos Metodológicos}

Atuam nos climas do Brasil cinco massas de ares e os Sistemas Frontais (SF), sendo duas de alta pressão e três de baixa. A massa Equatorial continental $(\mathrm{mEc})$ a massa Equatorial atlântica $(\mathrm{mEa}) \mathrm{a}$ massa Tropical continental são de baixa pressão e a massa Polar atlântica (mPa) e a Tropical atlântica (mTa), são de alta pressão. As massas de ares avançam ou expandem-se a partir dos seus centros de origem, predominantemente externos ao território brasileiro, assim, vão impondo as suas características e assimilando outras das áreas por aonde avançam.

As cartas sinóticas mostram, por meio das isóbaras, os centros de altas e de baixa pressão, também por meio da simbologia meteorológica específicas, interpretam-se outros elementos do tempo, por isso, e por meio da leitura e interpretação das cartas sinóticas do Brasil foi possível identificar as massas de ares que atuaram no Brasil, assim como acompanhar a evolução desde à entrada do sistema à dissipação.

Para a identificação dos sistemas atmosféricos utilizou-se as cartas sinóticas da Marinha do Brasil e as imagens de satélite no canal infravermelho do CPTEC-INPE, metodologia proposta por Pédelaborde (1970), e nas técnicas desenvolvidas por Borsato (2006). As imagens de satélite no canal infravermelho foram utilizadas como suporte para a identificação dos sistemas atuantes. 
Os sistemas atmosféricos considerados foram:o $\mathrm{SF}$, a $\mathrm{mTc}$, a $\mathrm{mTa}$, a $\mathrm{mPa}$, a $\mathrm{mEc}$ e a $\mathrm{mEa}$ (VIANELLO 2000; FERREIRA 1989; OLIVEIRA et. al, 2001; BISCARO 2007).

Para o registro dos sistemas atmosféricos, foram elaboradas tabelas em planilha do Excel®. Atribuíram-se valores numéricos (24) para os dias em que um único sistema atuou na região, e às vezes (12) para cada um, quando a região esteve sob a confluência entre dois sistemas e transformados em porcentagens. Ou seja, 24, quando um sistema atuou um dia inteiro, ou 12, quando atuou só parte do dia.

A pressão atmosférica lida nas cartas sinóticas foi considerada pressão baixa quando, aquém de 1013,2hPa, e alta, quando acima desse valor. Para esta pesquisa, a massa Tropical continental foi considerada atuante somente sob as condições de pressão baixa. Considerou-se também a configuração da célula ciclonal sobre a região de origem, "Grande Chaco".

O recorte temporal foi o inverno de 2016, sendo que a leitura e a contabilização das participações iniciaram no dia 20 de junho e finalizaram no dia 23 de setembro, totalizando 96 dias.

As nove localidades consideradas para a leitura das cartas sinóticas foram: Uruguaiana RS (-29,75 e -

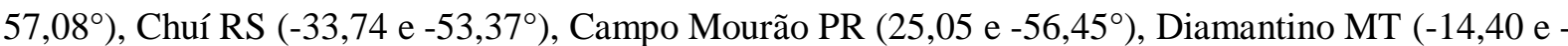
$\left.56,45^{\circ}\right)$, Benjamin Constante AM $\left(-4,38\right.$ e $\left.-70,03^{\circ}\right)$ Breves PA $\left(-1,68\right.$ e $\left.-50,48^{\circ}\right)$, Crateús CE $(-5,17$ e40,67), Itaberaba BA $\left(-12,52^{\circ}\right.$ e $\left.-40,67\right)$ e São Paulo (Mirante de Santana SP $(-23,50$ e -46,62 $)$ ). Para a espacialização dos dados foi utilizado o interpolador IDW (inverso da distância ao quadrado) no software livre Qgis, no qual também foram elaborados os mapas temáticos.

\section{Análise dos resultados}

A estação do inverno é a mais seca no Brasil, exceto para algumas áreas da Região Sul ou da Norte, as quais recebem volumes iguais ou acima do verificado na estação do verão. A distribuição das chuvas é consequência primária da participação dos sistemas atmosféricos. Para a estação em que prevalece a atuação dos sistemas de alta pressão, as chuvas escasseiam e essa situação é verificada para a maioria das regiões do Brasil na estação do inverno.

Condições ou estados do tempo propícios a chuva nesta época são resultado da interação entre os sistemas continentais e os polares. Sem querer se aprofundar nas considerações meteorológicas, o Sul do Brasil encontra-se nos limites das células da circulação geral da atmosfera, ou seja, na zona de maior contraste térmicos estabelecido nos limiares dos ventos de noroeste em confronto com os ventos de sudeste. Região denominada pela meteorologia como de frontogêneses. Segundo Gan (1992), a maior frequência frontogenética se verifica na faixa de $55^{\circ} \mathrm{W} / 32^{\circ} \mathrm{S}$ a $63^{\circ} \mathrm{W} / 42^{\circ} \mathrm{S}$ para os ciclos completos que atuam no continente sul-americano, essa zona é denominada de área de ciclogêneses. 
Para essa região, que inclui o Sul do Brasil é interessante atentar para outras peculiaridades que ocorrem nos episódios dos avanços das massas polares pelo interior do continente. $\mathrm{Na}$ zona de contato há um forte gradiente de temperatura e também de pressão, por isso, forma-se uma faixa de ar convergente, considerando que o ar polar apresenta circulação anticiclônicas e o ar continental, ciclônica. Essa zona de contato também é classificada como zona frontal ou simplesmente frente.

A grande maioria dos Sistemas Frontais que atuam no Brasil tem suas gêneses aquém do território brasileiro, principalmente na estação do inverno.

Para o inverno de 2016 e para os três estados do Sul. As participações dos sistemas frontais foram bastante semelhantes, considerando o tempo de atuação e também a rota percorrida habitualmente. As três localidades analisadas tiveram as seguintes participações: Chui RS, 18,9\%; Uruguaiana RS, 12,8\%; Campo Mourão PR, 17,2\% do tempo cronológico para os 96 dias analisados.

Há episódios em que a frontogêneses evolui a partir de Santa Catarina ou do Paraná, o que também justifica a menor participação na localidade de Uruguaiana.

Esse tempo maior para Chui em relação a Uruguaiana é consequência da configuração, enquanto no interior ela avança de sudoeste para sudeste, no litoral e Atlântico há em algumas situações o retorno ou oclusão do sistema, aumentando o tempo sob o Sistema Frontal. Por outro lado, a partir da latitude do trópico, os sistemas frontais escoam para o interior do Atlântico, por isso também, a participação em São Paulo é próxima às contabilizadas para o Sul. Há episódio em que a participação é até maior, consequência de um dos estágios da frente, frontólise sobre essa região. A Figura 01 mostra a espacialização dos sistemas frontais para o Brasil na estação do inverno 2016.

Para São Paulo, no Sudeste, a participação foi de 17,7\%. Essa participação próxima à verificada para o Sul do Brasil é consequência também da localização da Estação analisada em São Paulo, ou seja, sobre a linha do trópico de Capricórnio. Por isso, a grande maioria das frentes que avançam pelo Sul do Brasil, na estação do inverno avança também sobre o estado de São Paulo, mas especificamente na porção leste. Em pleno inverno, enquanto o sistema avança para o interior do Atlântico, geralmente na latitude do Sudeste do Brasil, a massa Polar atlântica que avança na retaguarda do sistema frontal invade o interior do território brasileiro pelo oeste e às vezes pode atingir o Sul da Amazônia (SERRA e RATISBONNA, 1945). 


\section{OS DESAFIOS DA GEOGRAFIA FÍSICA NA FRONTEIRA DO CONHECIMENTO Instituto de Geociências - Unicamp Campinas - SP 28 de Junho à 02 de Julho de 2017}

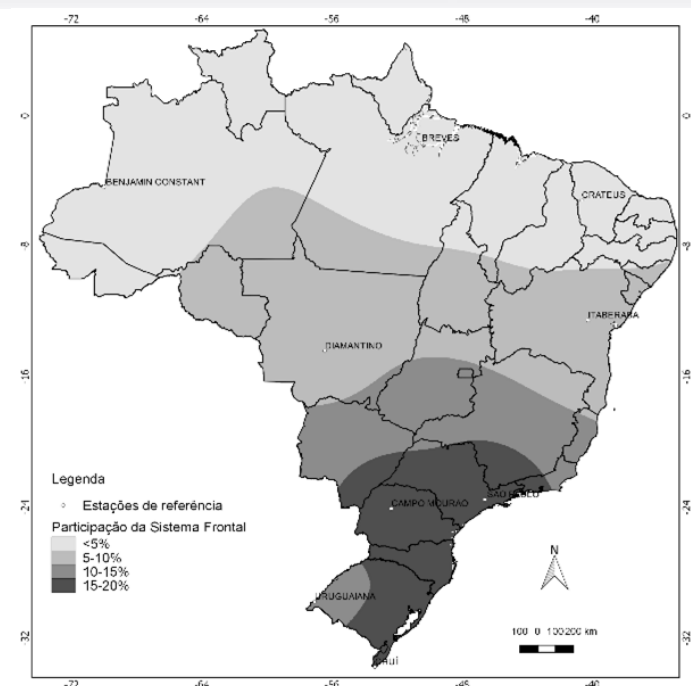

Figura 01 - Espacialização da Participação dos Sistemas Frontais no território Brasileiro no inverno de 2016.

Para o Sul do Brasil, a aproximação de um sistema frontal pode ser verificada com um ou dois dias de antecedência à sua passagem, o vento é moderado e, geralmente de NE, rondando para $\mathrm{N}$ e NW, com aumento da força à medida que a frente se aproxima; a pressão cai progressivamente e a temperatura se eleva com a compressão do ar, consequência do deslocamento do ar polar. As principais nuvens que antecedem a aproximação do sistema frontal são os cirrus, altostratus, cúmulos e nimbostratus. Em alguns episódios, observam-se linhas de instabilidades que se propagam paralelo à frente.

Para o Sul do Brasil, os principais episódios de chuvas, na estação do inverno, estão condicionadas à evolução dos sistemas frontais. A partir da linha do trópico de Capricórnio, para às vezes em que os sistemas frontais se propagam, as ocorrências das chuvas estão condicionadas à umidade relativa e também à rampa frontal. Por isso, não raro, há a passagem dos sistemas frontais sem registro de precipitação.

Para o inverno de 2016, o sistema frontal atuou em somente $8,5 \%$ do tempo cronológico para a localidade de Diamantino MT e 6,8\% em Itaberaba na Bahia. Para Benjamin Constant no Amazonas, Breves no Pará e Crateús no Ceará não houve participação.

Para o Sul do Brasil, depois da passagem da frente, o vento passa a soprar de sudoeste ou sul e a temperatura cai. A queda da temperatura também está condicionada intensidade da massa Polar. Para o período mais frio, quando, preferencialmente ela avança pelo interior do continente, a queda é brusca e pode ser intensa, a nebulosidade diminui e em poucas horas o céu fica aberto. Para os estados do Sul do Brasil é comum a formação de geadas noturnas e também precipitações de neve nas áreas de maiores altitudes.

Os episódios de avanços da massa Polar, no inverno segue habitualmente, a calha do Rio da Prata/Paraná e pode alcançar a Amazônia. Embora a partir da região central do Mato Grosso, o 
escoamento da Troposfera segue-se de leste para oeste. Por isso, a massa Polar avança com mais frequência para Rondônia e sul do estado do Amazonas e raramente para o Sul do Pará.

Na estação do inverno de 2016 a localidade com mais tempo sobre a atuação da mPa foi Chuí no Rio Grande do Sul com 67,5\% do tempo cronológico, seguido por Uruguaiana, também no Rio Grande do Sul com 66,3\% e Campo Mourão no Paraná com 46,9\%. Como neste inverno, um grande número de sistemas polares avançou pelo interior do continente, a participação em Diamantino MT foi de 27,6\%. É interessante observar que a massa Polar, ao avançar sobre o continente impõe suas características e assimila as características por onde avança, por essa razão, o frio intenso que é a principal característica sensitiva para o Sul, perde gradativamente essa característica à medida que avança. $\mathrm{Na}$ região Centro Oeste, registram-se queda acentuada na temperatura no Mato Grosso do Sul. Nos demais estados, a queda é pouco acentuada. Nos dias sequentes à passagem, a temperatura eleva-se gradativamente e em dois ou três dias as modificações se completam e o ar polar se tropicaliza.

A massa Polar atlântica, raramente atinge a região Norte, exceto quando ela for intensa e avançar, preferencialmente pelo interior do continente. Neste inverno, contabilizou-se a participação em Benjamin Constante no Amazonas em apenas 3,3\% do tempo cronológico. Essa participação é contabilizada, considerando apenas a pressão atmosférica e a configuração das isóbaras nas cartas.

A massa Polar também avança além da região Sudeste pela costa Atlântica. Para este inverno, a participação em Itaberaba na Bahia foi de 5,2\% do tempo cronológico. O mapa da Figura 02 mostra a espacialização da participação pelo território Brasileiro neste inverno.

No inverno, ao sul do trópico o escoamento global se dá de oeste para leste. Assim, os sistemas Polares, mesmo aqueles que avançam pelo interior do continente, a partir do segundo ou terceiro dia, iniciam o processo de escoamento para leste e no Atlântico são assimilados pela Alta Subtropical do Atlântico. Por isso, a participação no Sudeste, principalmente para o estado de São Paulo é próximo ao verificado no estado do Paraná. 


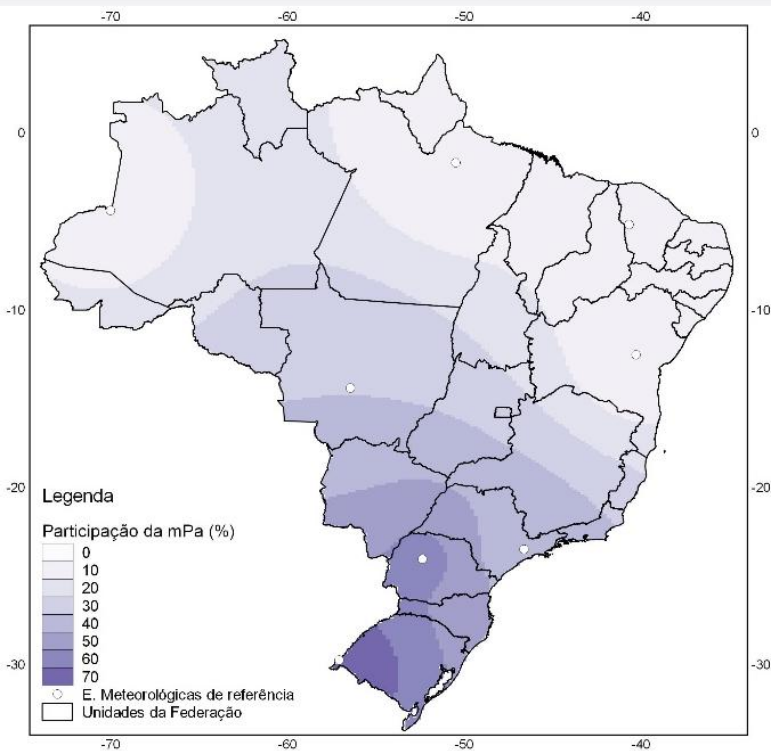

Figura 02 - Espacialização da participação da massa Polar atlântica nos estados do tempo para território Brasileiro no inverno de 2016.

Na estação do Mirante de Santana, São Paulo, a participação da mPa neste inverno foi de 43,8\%. Em Breves no Pará e em Crateús no Ceará não houve participação.

Borsato e Mendonça (2013) estudaram a participação da massa Polar atlântica para a série 2002 a 2010 e verificaram que, para Campo Mourão, a participação média foi de 50,9\%. O ano com menos participação foi 2006 , com $45,2 \%$ e com mais, foi 2003 , com $64,7 \%$. Esses dados mostram que para a estação do inverno de 2016 a participação esteve abaixo da média (46,9\%). A hipótese de que tenha havido mais participação não se confirmaram, inclusive, a participação aproximou-se da menor já verificada por Borsato e Mendonça (2013), que foi 45,2\% em 2006.

O segundo sistemas de alta pressão, que influencia mais intensamente na borda leste do Brasil, principalmente do Sudeste, é a massa Tropical atlântica. Seu centro de origem é a Alta Subtropical do Atlântico Sul (ASAS). Anticiclone quente e semi-estacionário (ITO e AMBRIZZI, 2000). Essa massa de ar mantém as características do anticiclone, embora modificada, dada as características que ela adquire à medida que adentra ao continente.

Os meteorologistas acompanham a evolução do ASAS diariamente, isto porque, esse anticiclone influencia na dinâmica climática do Brasil. Ele poderá gerar bloqueios atmosféricos e impedir os avanços dos sistemas frontais (MUSK, 1988). Também no inverno, o centro do ASAS aproxima-se do continente, por isso, crista avança para o interior do Brasil e essa massa de ar domina o estado do tempo em todo o Sudeste, sul do Nordeste, leste do Centro Oeste e a borda norte da região Sul do Brasil. Por isso, na estação do inverno, essa massa gera estabilidade atmosférica. A mapa da Figura 03 mostra a espacialização da participação dessa massa de ar no território brasileiro no inverno de 2016. 


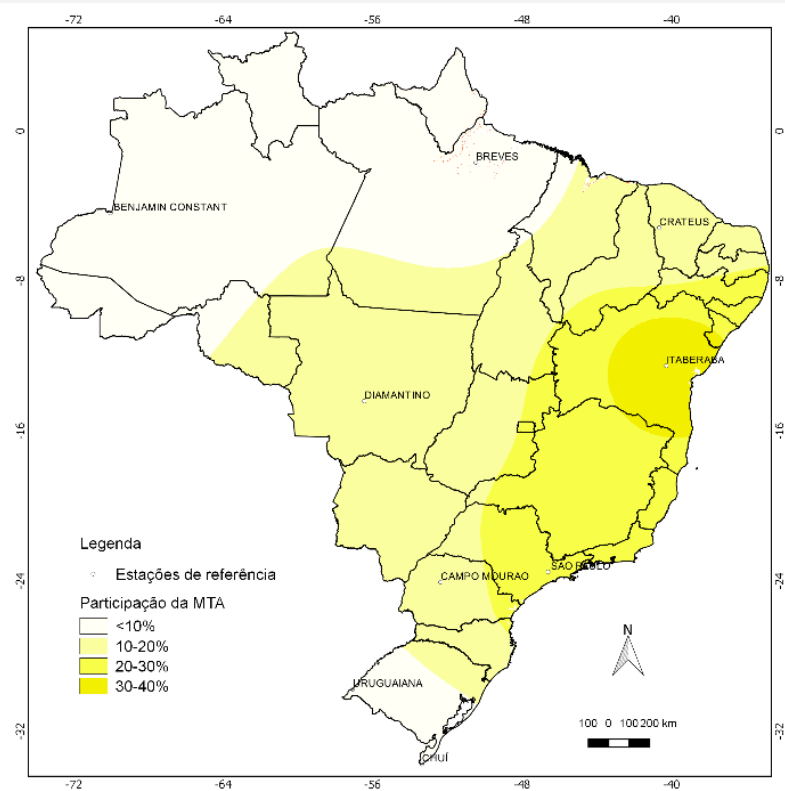

Figura 03 - Espacialização da participação da massa Tropical atlântica nos estados do tempo para território Brasileiro no inverno de 2016.

Para o inverno de 2016, a localidade com mais participação foi Itaberaba BA, com 37,3\% do tempo cronológico, seguido por São Paulo com 29,7\%. Em Campo Mourão PR a participação foi de 17,2\%, em Diamantino MT foi de 14,6\%, em Crateús CE de 13,0\%. Nos extremos sul foi ainda menor, com 3,1\% no Chuí RS e 2,6\% Uruguaiana; e no extremo norte, Benjamin Constant AM e Breves PA, não houve participação.

Estudos da atuação da massa Tropical atlântica para o Centro Sul do Brasil para a série histórica 2002 a 2010 mostraram que a participação média dessa massa de ar em Campo Mourão foi de 14,4\% (BORSATO e MENDONÇA, 2013). O mesmo estudo mostrou também que a variação interanual é ampla. Em 2009, a participação foi de apenas 5,9\% e para o ano de 2004 se ampliou para 21,5\%. Dessa forma, verifica-se que para o ano de 2016 foi um pouco acima daquela média.

A dinâmica dos sistemas atmosféricos mostra que à medida que a massa Polar se desloca para o interior do Atlântico, a Tropical atlântica expande-se para o interior a partir do Sul do Nordeste do Brasil e a massa Tropical continental se amplia a partir do oeste da região Sul do Brasil. Segundo a Meteorologia, na estação do inverno, o centro anticiclônicodo ASAS, inclina-se em altitude para o oeste e influencia nas condições do tempo em quase todo o Centro Sul do Brasil (BASTOS e FERREIRA, 2000).

Um sistema atmosférico com ampla atuação no interior do Brasil é a massa Tropical continental, seu centro de origem é na região do Grande Chaco (MALDONADO, 2006). Na estação do inverno principalmente, essa massa de ar se expande a partir do centro de origem e com o deslocamento da massa Polar atlântica para o interior do Atlântico, ela domina os estados do tempo a partir do oeste do Rio Grande do Sul, avançando também, sempre a partir do oeste dos estados de Santa Catarina, 


\section{OS DESAFIOS DA GEOGRAFIA FÍSICA NA FRONTEIRA DO CONHECIMENTO \\ Instituto de Geociências - Unicamp \\ Campinas - SP \\ 28 de Junho à 02 de Julho de 2017}

Paraná, Mato Grosso do Sul. Às vezes, avança também para o Mato Grosso e Goiás, Minas Gerais e São Paulo.

Essa massa de ar caracteriza-se por apresentar pressão baixa, elevada temperatura e também baixa umidade relativa. Às vezes ela ganha umidade, arrastada para a região pela Corrente de jato de Baixo Nível (MARENGO e SOARES, 1999). Os dias em que essa massa de ar domina os estados do tempo no Centro Sul do Brasil, ela gera as ondas de calor (BORSATO e HEIRA, 2015).

Na estação do Inverno de 2016, a participação no Brasil, analisada e contabilizada a partir das estações estudadas foi: 18,2\% para Campo Mourão e Uruguaiana, 21,9\% para Diamantino, 10,4\% para Chuí, 6,8\% para São Paulo e 3,6 para Itaberaba (Figura 04).

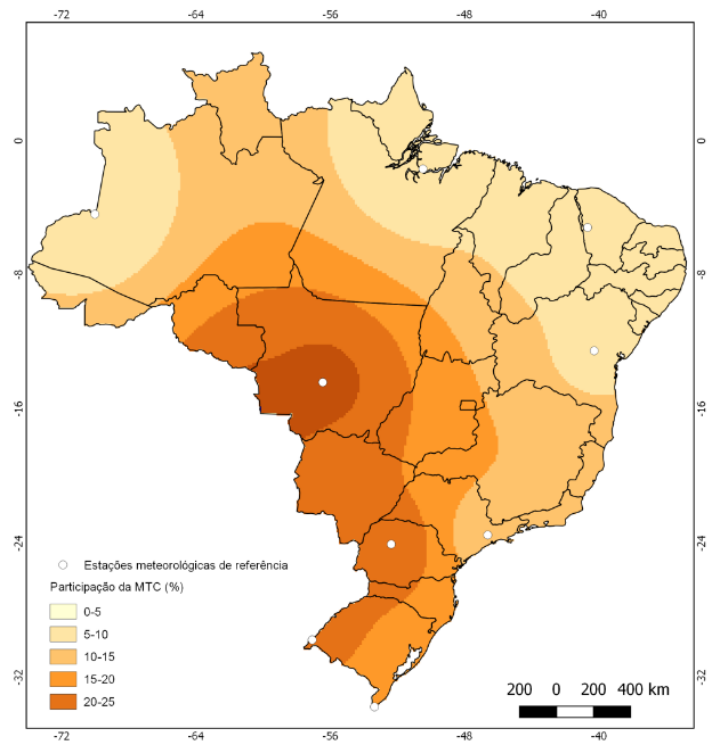

Figura 04 - A- Espacialização da participação da massa Tropical continental nos estados do tempo para território Brasileiro no inverno de 2016.

$\mathrm{Na}$ estação do inverno prevalecem os sistemas de alta pressão. As massas de ares avançam a partir de seus centros de origem, impõe suas características e assimilam as características das áreas que percorrem, por isso, perdem as suas características originais, ou seja, são modificadas e quanto mais tempo permanecer sobre um território, mais intensas são as modificações. Essas considerações corroboram para justificar a intensa participação da massa Tropical continental na estação do inverno em território brasileiro e as sucessivas ondas de calor.

$\mathrm{Na}$ estação do inverno, o tímido aquecimento do hemisfério sul contribui para a ampliação dos sistemas de alta pressão e redução dos de baixa. Por esse motivo a massa de ar Equatorial continental e a Equatorial atlântica têm suas atuações limitadas nesta estação (Figuras 05 A e B).

A massa Equatorial continental que, no verão se amplia atuando em vastas áreas do Centro Sul do Brasil, no inverno, raramente atinge esta mesma área, com também ocorreu em 2016. A participação se limitou ao centro oeste da Amazônia. Assim, em Benjamin Constant foi 96,7\%, mas já em Breves caiu para $25,5 \%$, em Itaberaba para 18,9\% e em Diamantino para 17,5\%. (Figura 05A). 

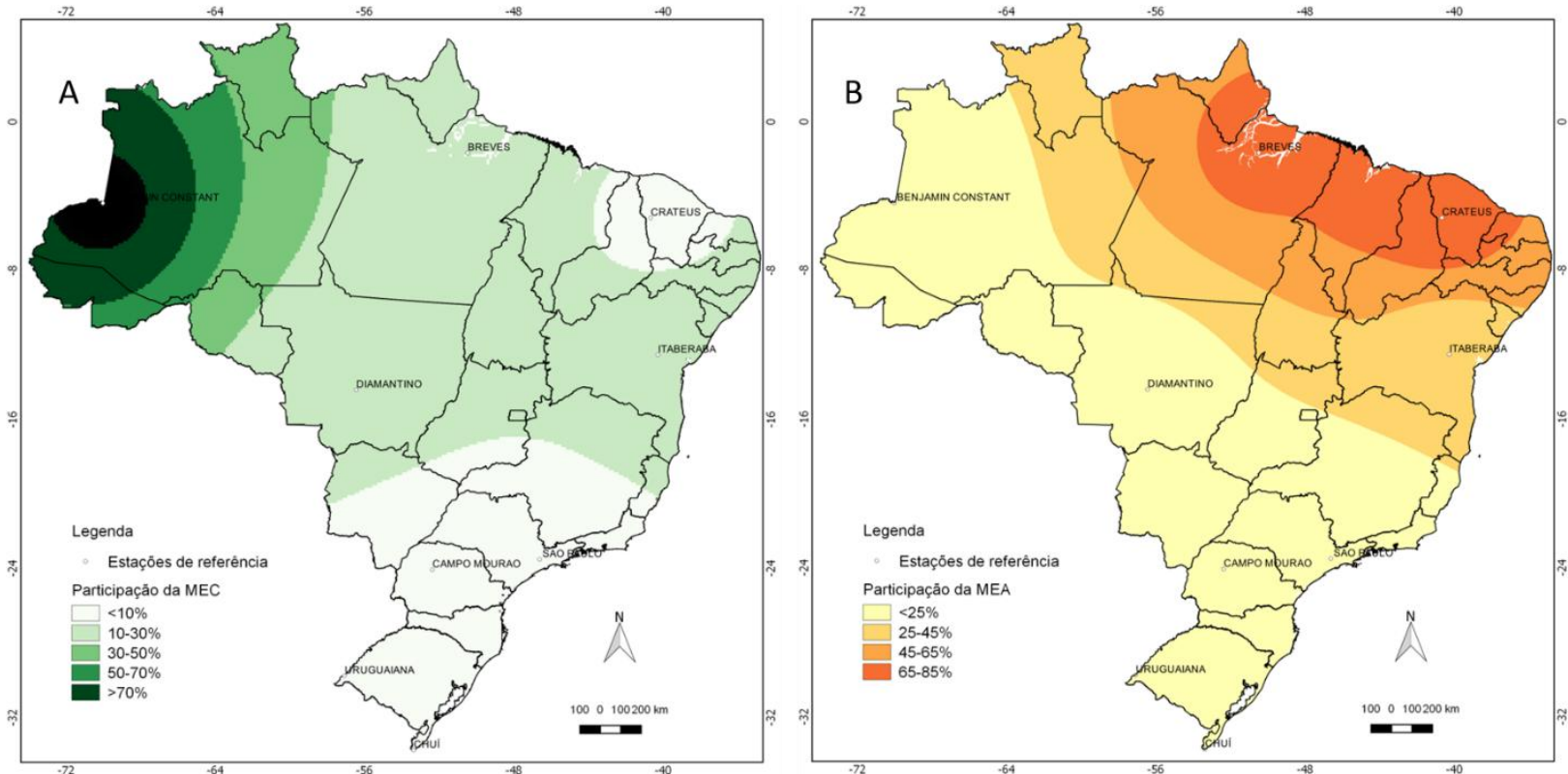

Figura 05 -Espacialização da participação da massa e Equatorial continental (A) e Equatorial atlântica (B) nos estados do tempo para território Brasileiro no inverno de 2016.

A massa Equatorial atlântica mantém as características da ASAS, ou seja, a pressão oscila acima da pressão normal $(1013,2 \mathrm{hPa})$. Essas características proporciona estabilidade atmosférica. Mesmo quando ela se expande e avança para o interior do Brasil, essas características se mantêm, ela ganha calor continental e a pressão baixa, mesmo assim, não proporciona chuva, exceto em algumas áreas do litoral onde a elevação do relevo proporciona a ascensão das correntes de ar.

Para o inverno de 2016, o extremo norte do Nordeste e o leste do Norte foram as áreas de mais atuação dessa massa de ar. Em Crateús CE, a participação foi de 81,8\%, em Breves PA 74,5\%, em Itaberaba BA $28,1 \%$ e em Diamantino MT, 9,9\%. As demais localidades, não se verificaram a participação nessa estação. A Figura 05B mostrou a espacialização dessa massa de ar em território do Brasil.

\section{Considerações Finais}

$\mathrm{Na}$ Tese de doutoramento, Borsato (2006) estudou a dinâmica das massas de ares na Bacia do Alto Rio Paraná, para o período de 1980 a 2003. Para essa série, a participação da massa Polar atlântica no inverno em Maringá, cidade próxima de Campo Mourão, foi de 50,9\%. Em 2016, ela atuou em 46,7\% do tempo cronológico considerado. Esses dados corroboram para não confirmar a hipótese de maior participação da massa Polar atlântica no inverno de 2016.

O estudo não considerou a intensidade das massas Polares atuantes. É possível que, para o inverno de 2016, a intensidade tenha sido maior, razão porque os meios de comunicação noticiaram com mais ênfase a participação desse sistema atmosférico. Também é importante considerar que hoje se veiculam mais notícias que abordam mudanças climáticas, por isso, a mídia deu mais ênfase às previsões e a participação do frio no Sul do Brasil. 
28 de Junho à 02 de Julho de 2017

Segundo o Instituto Agronômico do Paraná (IAPAR, 2016), para todo o ano de 2016 ocorreu a formação de geadas em 19 dias, sendo que 16 destas ocorrências foram na estação do inverno. Segundo o mesmo Instituto, em 2015 foram apenas dois dias. Por outro lado, em 2012 foram 27 dias com registros de geadas e, em 2009, 25 dias. Dessa forma, verifica-se que para 2016, considerando apenas os dias com registros de geadas no Paraná, a dinâmica da massa Polar atlântica comportou-se dentro do esperado para a estação.

Uma segunda hipótese, que não foi abordado porque o recorte temporal limitou-se aos meses do inverno, é que pode ter ocorrido a participação mais efetiva da massa Polar atlântica na estação do outono e também da primavera, principalmente na segunda metade do outono e primeira metade da primavera, inclusive com friagem intensa para o Sul do Brasil. Essas ondas de frio fora da estação do inverno podem ter sido interpretadas como inverno mais rigoroso pelos meios de comunicações. Isto nos leva a dar continuidade ao trabalho, analisando um segmento temporal mais longo.

\section{Agradecimentos}

A publicação e apresentação deste trabalho foi financiado pela Fundação Araucária de Apoio ao Desenvolvimento Científico e Tecnológico do Estado do Paraná. EDITAL 05/2016 - PRPPG/Unespar Apoio à Participação de Docentes em Eventos Científicos.

\section{Bibliografia}

BASTOS, C.; FERREIRA, N.; Análise Climatológica da Alta Subtropical do Atlântico Sul. In: XI CONGRESSO BRASILEIRO DE METEOROLOGIA, 2000. Anais... Rio de Janeiro, p. 612-619, 2000.

BORSATO, V. A. A participação dos sistemas atmosféricos atuantes na bacia do Auto Rio Paraná no período de 1980 a 2003. 2006129 p. Tese (Doutorado em Ciências Ambientais) - Nupélia, UEM, Maringá.

BORSATO, V. A.; MENDONÇA, F. A.A Participação dos sistemas atmosféricos na estação do Inverno de 2012 no Centro Sul do brasil. In: XV SBGFA - XV Simpósio brasileiro de Geografia Física Aplicada, 2013, Vitória ES. Anais do XV SBGFA. Vitória ES, 2013. p. 336344.

BORSATO, V. A. e HEIRA, M D, Onda de calor em outubro de 2014 e os sistemas atmosféricos - Revista Equador (UFPI), Vol. 4, N 3, (2015). Edição Especial XVI Simpósio Brasileiro de Geografia Física Aplicada. Teresina- Piauí. Home <http://www.ojs.ufpi.br/index.php/equador> consultado em 23/12/2016.

BISCARO, G. A. Meteorologia Agrícola Básica, $1^{\circ}$ edição, UNIGRAF - Gráfica e Editora União Ltda. Cassilândia - Mato Grosso do Sul, 2007, 87p.

FERREIRA, C.C. Ciclogêneses e ciclones extratropicais na Região Sul-Sudeste do Brasil e suas influências no tempo, INPE-4812-TDL/359, 1989. INPE - 4812 - TDL/359, 93p.

INSTITUTO AGRONÔMICO DO PARANÁ IAPAR. Histórico de Geadas. Mapas com as temperaturas mínimas do abrigo registradas nos dias em que ocorreu geada em algum ponto do Paraná. Disponível em $\langle$ http://www.iapar.br/modules/conteudo/conteudo.php?conteudo=2056> consultado em 22 de dezembro de 2016.

ITO, E. R. K.; AMBRIZZI, T.; Climatologia da posição da alta subtropical do atlântico sul para os meses de inverno. Anais do XI Congresso Latino-americano e Ibérico de Meteorologia, 2000, Rio de Janeiro. A Meteorologia Brasileira além do ano 2000. Rio de Janeiro: Sociedade Brasileira de Meteorologia, 2000. p. 860865.

GAN, M. A.; Ciclogêneses e ciclones sobre a América do Sul. 1992. 221 f. Tese (Doutorado em Meteorologia) Instituto Nacional de Pesquisas Espaciais, São José dos Campos, São Paulo, 1992. 
MARENGO J. A; SOARES WR.; Episódios de Jatos de Baixos Níveis ao Leste dos Andes durante 13-19 de abril de 1999. Revista Brasileira de Meteorologia, 17(1): 35-52 2002.

MALDONADO, P.; Atlas delGranChaco americano; ilustrado por Martin Naumann - 2a . Edición - Marzo 2006. - Buenos Aires: Agencia Alemana de CooperacionTecnica, 200696 p.

MUSK, L.; Weather Systems. New York: Cambridge University Press. EditionUnstatededition (April 29, 1988) 1988. P 160.

OLIVEIRA, L.L. de; VIANELLO, R. L. e FERREIRA, N.J. Meteorologia Fundamental; 2001, Edi FAPES Livraria e editora, Erechim

PÉDELABORDE, P. Introduction a l'étudescientifiqueduclimat. Paris: Sedes, 1970.

SERRA, A. e RATISBONNA, L. As ondas de frio da bacia Amazônica. Boletim Geográfico, ano III, nº 26, maio 1945 - Transcrição. Serviço de meteorologia. Ministério da Agricultura, 1941, p 172 - 206.

VIANELLO, R. L. Meteorologia básica e aplicações. Universidade Federal de Viçosa. Editora UFV 2000. p 450. 